\title{
How an economic crisis may improve your management skills Strategies for making it through uncertain times
}

eadership is generally defined as infl uZencing others to work willingly toward achieving objectives. The current economic climate that we find our colleagues, staf, and selves working in is unfamiliar and stressful to many of us. Many or ganizations are cutting budgets, including workforce, in order to remain viable. Now more than ever, managers need to be actively involved in creating a positive work environment and motivating staff to continue giving their best despite a highly tense situation. Employees look to management for leadership, guidance, and for the tools and resources necessary to make it through this crisis.

Successful management involves managing people in a way that motivates and enables them to work at their highest levels of productivity and in har mony with one another so that the organization is thriving in terms of efficiency, service, effectiveness, quality, and value. Good management is always vital to an organization. During times of uncertainty and stress, it is essential.

Many of the strategies employed during a crisis are the same as those used in everyday management. The principal management tool is also the most broad and encompassing-communication. Communication with staff is always central to an or ganization's success, but it is especially critical during periods of pressure. Keeping staff informed will alleviate anxiety and keep them focused on or ganizational goals. Connecting with staff and showing compassion and concem for their well-being helps reinforce trust and support.

\section{Key points to remember regarding communication}

- Address the rumor mill. Gossip and speculation tend to skyrocket during economic crises. Ignoring it only allows it to fester and preoccupy staf. Open communication about what is actually happening, and immediately dispelling rumors or half-truths, will keep staf $\mathrm{f}$ focused on their work and create an environment of trust. Remember , in the absence of information the worst-case scenario is often assumed.

- Communicate in person. E-mail should not replace face time with staff. Regular staff meetings and/or one-on-one conversations work best when critical or complex information must be communicated. Anticipate the kind of infomation employees want to know and what types of questions are likely to ask.

- Be participatory. Share the vision. Employees are more willing to make changes and take on more responsibility oitasks when they understand how it supports the lar ger objectives of the or ganization. Often the people who know a process or service best are those who peform them on a daily basis. If services or workfl ow need to be revised or replaced, involve staf $\mathrm{f}$ in the discussion. Brainstorming the solution to organizational challenges together gives staff a voice in the outcome and motivates them to put forth their best effort.

Mary Carmen Chimato is head of access and delivery service at North Carolina State University,e-mail: mary_chimato@ncsu.edu

(c) 2009 Mary Carmen Chimato 
Being a manager requires caring for employees. People who are shown care work more effectively with and for the people who show that care. These people feel better and are more positive to be around. Being a caring and compassionate manager does not have to be a counseling activity. It simpl means showing concern for staff in ways that help them improve performance and grow. During tough times managers may feel the need to become more hard-edged and demanding in an effort to get more out of less people or resources. This sudden desire for better peformance may manifest itself as criticism or nitpicking and may place additional stress upon employees resulting in poor performance.

\section{Caring for staff happens in many ways}

- Practice active and attentive listening. Listening means knowing what others have said, or meant to say, and leaving people with the feeling that they have had their opinions or concems heard. Do not interrupt. Be able to paraphrase. Listen for underlying meaning. Maintain eye contact. Take notes. Do not frown or make any other derogative facial expressions. Good listeners ask questions to get a better understanding of what is being communicated. Once the conversation has ended, repeat the key points or issues. If necessary, schedule a follow-up discussion.

- Share and disclose. Share your thinking on a work issue and ask employees for their input or advice. Pass on pieces of information that may help people do their jobs better or broaden their perspective. When announcing changes or any other important decision, share how you arrived at the decision; explain intentions or reasons. This can help employees understand why things are happening and feel less put upon.

- Be available and personal. Of fer opportunities for individuals or small groups to voice their worries or concems even if there is no further information or answers that can be given at that time. Know several personal things about staff. By asking a few personal questions you may make it easier to grow trust and cultivate relationships.
During hard times organizations are asked to do more with less, requiring a reassessment of work and services an d providing the opportunity to reallocate staf $f$ resources and revise or eliminate processes. Developing a comprehensible p lan, s etting goals, and communicating clear expectations are the necessary steps towards identifying and eliminating work, which may result in organizational improvement. Nothing assists in moving workflow along better than a clear plan. It helps the staf that has to follow it and leads to better use of resources. Planning in advance anticipates and identifi es problems before they occur.

\section{What a good planning process involves}

- Laying out tasks and work. Break the work down into process steps. Ask employees to contribute to this process to ensure that no tasks or details are overlooked and omitted.

- Setting goals. Employees who are given specific goals usually per form better than those who are not. Goals should be challenging, but not so difficult that they appear impossible or unrealistic. Whenever possible, goals should include target dates or deadlines for accomplishments and be set in collaboration with both management and staff. Since ability is an important deteminant of performance, giving staf $f$ input and the opportunity to ask for assistance, clarifi cation, or further training helps guarantee that goals will be met.

- Keeping expectations clear and concise. Often employees are not entirely clear on what is expected of them in their jobs. Ensuring that staf $f$ know what they should be doing is critical during an economic crisis when there could be fewer people performing the work. Clear, concise expectations that transition with the changes in the larger organizational goals and workfbw are key to earning staff support and buy-in.

\section{Staff recognition}

The biggest mistake a manager can make is 
forgetting to recognize individual and group successes. It is easier to identify weaknesses than to recognize people when they are performing well.

Traditionally organizations recognize outstanding performance with salary increases, but with tight economic times the opportunities to provide financial rewards are limited. In hard times staf $\mathrm{f}$ will regularly hear bad news, so the simple recognition of a job well done can go very far in bringing up morale and self-esteem.

Staff recognition is not solely about improving and maintaining staf $\mathrm{f}$ morale and esteem, it also highlights the kind of performance that is desired and expected in the workplace. It is an important communication tool that reinforces the behaviors and actions that managers want to see repeated.

Recognizing staff is inexpensive and does not require great efort. It can be as simple as writing an e-mail or handwritten thank you note for putting in some extra effort to meet a deadline, or it can be done in a public setting, such as a staff meeting, where an employee is recognized for providing exemplary ser vice. Praising a staff member after they fnish dealing with a difficult situation or customer is another way of letting them know that as a manager you value their work. The most effortless form of respect and appreciation a manager can give is to say thank you.

Above all, managing during uncertain times or crisis requires the leader to remain positive and upbeat about what is being accomplished or changed without dwelling on the cause of the situation, laying blame, or indulging complainers. Creating an engaging and positive work environment helps staf $\mathrm{f}$ become resilient. Management is a demanding job that requires maximum effort without a guaranteed positive return.

Any type of stress exponentially increases the difficulty of the work; however, these are the very situations where your skills and talents are put to the test, and often you and your staff come out a stronger more collaborative, more open, and more productive unit. $\varkappa$

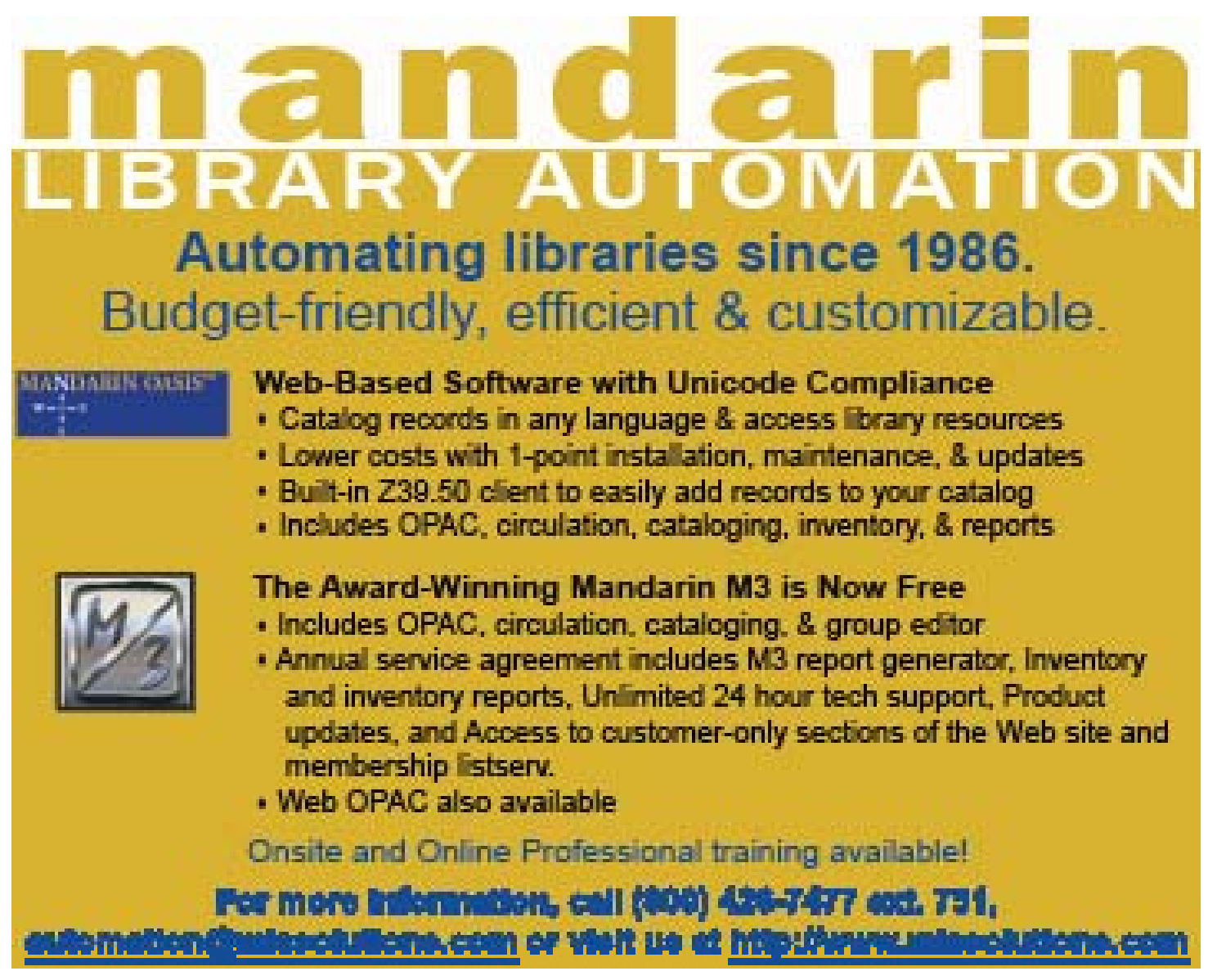

